\title{
LEITURAS DA CRÍTICA: MEDIAÇÕES E DESLOCAMENTOS
}

\author{
Cleber Araújo Cabral
}

Mestrando em Letras - Estudos Literários / UFMG

\begin{abstract}
RESUMO
Este texto propõe uma leitura do conceito de crítica a partir das discussões sobre a situação e a prática da crítica literária no Brasil, hoje. Procura-se refletir acerca do compromisso do crítico como mediador da leitura de literatura e com a leitura da contemporaneidade.
\end{abstract}

\author{
PALAVRAS-CHAVE \\ Literatura, crítica, mediação
}

\section{INTRODUÇÃO}

A leitura é, pois, (...) a execução própria da crítica. ${ }^{1}$

Falência, morte, esgotamento, demissão, silêncio, mal-estar, crise. Ao realizarmos um levantamento textual na internet, esses são alguns dos termos que encontramos associados à noção de crítica literária e a seu exercício hoje no Brasil. Argumenta-se que ela tem perdido sua função e seu lugar como leitura avaliativa (ou julgadora) da literatura, atuando apenas como veículo de marketing, sendo reduzida à produção de press releases para os lançamentos do mercado editorial. Mas qual seria a função da crítica? E seu compromisso?

A partir desse breve quadro, gostaria de propor, com este ensaio, uma leitura das relações entre a atividade crítica como meio de reflexão e o papel do crítico como intelectual. Para tanto, sugiro a seguinte aproximação: primeiro, a partir de uma conferência de Michel Foucault, ${ }^{2}$ apresentar um percurso histórico-filosófico, de modo a precisar, no Ocidente

\footnotetext{
${ }^{1}$ SEGRE citado por NUNES. Crítica literária no Brasil, ontem e hoje, p. 52.

${ }^{2}$ FOUCAULT. Qu'est-ce que la critique? Critique et Aufklärung.
} 
moderno, o momento de emergência da noção de crítica como crítica do conhecimento. $\mathrm{O}$ segundo movimento vincula a crítica à noção de medium de reflexão. O terceiro movimento consiste no levantamento de algumas representações do crítico, que também aborda a questão do compromisso da crítica literária com a atualidade. Por fim, um quarto movimento se constitui como uma tentativa de relacionar as formulações acima com considerações sobre as relações entre a crise da crítica, da literatura e do cânone.

Os quatro movimentos teóricos podem ser descritos como: arqueo-genealogia $^{3}$ da crítica, a crítica como mediação, sociologia do crítico como intelectual e considerações para um deslocamento da crítica. Se há um intento com tal exercício de articulação, posso dizer que este se constitui na tentativa de compreender como a função da crítica (enquanto mediação das possibilidades de leitura do presente) está relacionada à práxis do crítico na contemporaneidade. Outra questão subjacente que se impõe, em razão das discussões sobre a crise da crítica literária vivenciada hoje, trata da necessidade de repensarmos os conceitos que norteiam tal atividade: o de literatura e o de cânone.

Tenho em mente que tal recorte se mostra deveras amplo, mas o impulso que o alimenta não é o de uma totalização, de uma leitura universalizante, mas o de elaborar um “quadro volátil” do contexto atual. Tal esboço é circunstanciado a uma "atitude localizada"4 que remete ao ato de correr o risco do pensamento - ou, em outros termos, de colocar a questão sobre o limite (e o compromisso) de nosso próprio saber acerca dessa práxis a que nomeamos por crítica.

\section{A CRÍTICA COMO ATO DE OUSAR SABER}

E se é preciso colocar a questão do conhecimento na sua relação com a dominação, seria de início e antes de tudo a partir de uma certa vontade decisória de não ser governado, esta vontade decisória,

\footnotetext{
${ }^{3}$ A arqueologia seria um método de descrição do sistema (ou arquivo) que rege o surgimento e as condições históricas dos enunciados, enquanto a genealogia se ocupa de uma analítica do saber em termos de estratégias e táticas de exercício de poder/governamento, de modo a situar o saber no âmbito do agonismo. Para mais esclarecimentos, ver os verbetes Arqueologia e Genealogia CASTRO. Vocabulário de Foucault - um percurso pelos seus temas, conceitos e autores, p. $42-43$ e p. 184-187, respectivamente.

${ }^{4}$ Por atitude localizada compreende-se uma reflexão prática circunstanciada a um evento ou contexto, teorização esta destituída de pretensões universais ou totalizantes. DELEUZE. Os intelectuais e o poder (com Michel Foucault), p. 266.
} 
atitude ao mesmo tempo individual e coletiva de sair, como dizia Kant, de sua menoridade. Questão de atitude. ${ }^{5}$

No ano de 1978, Michel Foucault proferiu a conferência "Qu'est-ce que la critique? Critique et Aufklärung”, ${ }^{6}$ na qual elege como temas a crítica e a herança crítica da Aufklärung kantiana. Seu intuito: apresentar um percurso histórico-filosófico das relações entre crítica e Esclarecimento, de modo a traçar a especificidade da crítica, entendida como exame das condições a priori do conhecimento e da experiência, bem como os rumos da filosofia contemporânea a partir dessa problematização. A conferência tem dois momentos: na primeira parte, Foucault tece observações acerca do projeto crítico kantiano e as relações entre a governamentalização e a Aufklärung; no segundo momento, discorre acerca dos problemas de método de suas pesquisas arqueológico-genealógicas.

Segundo Foucault, a crítica, compreendida como atitude do sujeito em relação ao conhecimento de si e sobre o momento presente em que vive, relaciona-se com as seguintes questões: o que penso? Qual o limite do que posso saber sobre algo? Qual a ideia que tenho sobre o ato de conhecer? Qual a legitimidade de tal possibilidade de conhecimento? O que se diz e se entende por saber? Desse modo, ao relacionar os problemas da autonomia e do conhecimento, coloca-se outra questão: a dos modos de exercício de governo dos homens.

De acordo com Foucault, a crítica, entendida como figura da racionalidade moderna, como éthos que caracteriza a autonomia (ou maioridade do pensamento), ocorre como atitude que se efetua face a um determinado modo de governo dos homens, que seria uma arte de direcionamento da consciência (ou governamentalidade). Tal direcionamento pastoral se faria necessário, dada a menoridade da humanidade, incapaz de conhecer as condições de sua natureza e, portanto, de zelar por si mesma.

Em sua leitura da conferência de Foucault, o filósofo Oswaldo Giacoia Júnior esclarece que, "para Kant, tal menoridade seria uma incapacidade de servir-se do próprio entendimento sem a direção de outrem”, 7 situação em que a humanidade é mantida principalmente pela atuação combinada da religião (relação com a própria natureza mediada

\footnotetext{
${ }^{5}$ FOUCAULT. Qu'est-ce que la critique? Critique et Aufklärung, p. 19.

${ }^{6}$ Esse texto foi publicado no Bulletin de la Societé Française de Philosophie (année 84, n. 2, avr.-juin 1990). Por se tratar de um texto de difícil acesso e até o momento não editado ou traduzido para a língua portuguesa, utilizei a tradução que se encontra disponível no site Espaço Michel Foucault (http://filoesco.unb.br/foucault/), mantido por Wanderson Flor Nascimento.

${ }^{7}$ GIACOIA JÚNIOR. Crítica e filosofia, p. 46.
} 
pela linguagem), do direito (relação com as condições de legitimidade e verdade) e do conhecimento (relação do ser consigo mesmo e com a experiência).

Nesse jogo entre formas de direcionamento/governo da consciência e a crítica (ou como diz Foucault, entre governamentalização ${ }^{8}$ e crítica), a crítica se apresenta como uma arte da inservidão voluntária, aquela da indocilidade refletida, em que se relacionam os problemas do governo de si e da autonomia. Ao atuar como possibilidade do sujeito de se opor ao controle e à exploração, a atitude crítica abre caminho para a possibilidade de saber e questionar a respeito dos próprios limites, de direcionar a si mesmo e de rebelar-se contra os modos de direcionamento da própria consciência. Como coloca Foucault,

(...) vê-se que o foco da crítica é essencialmente o feixe de relações que amarra um ao outro, ou um a dois outros, o poder, a verdade e o sujeito. (...) a crítica é o movimento pelo qual o sujeito se dá o direito de interrogar a verdade sobre seus efeitos de poder e o poder sobre seus discursos de verdade; pois bem, a crítica será a arte da inservidão voluntária, aquela da indocilidade refletida. A crítica teria essencialmente por função o desassujeitamento no jogo do que se poderia chamar, em uma palavra, a política da verdade. ${ }^{9}$

Ao retomar o mote de Horácio “Ousa saber!” (sapere aude) empregado por Kant, Foucault insiste na ousadia que há no ato crítico de ousar saber sobre si, de interrogar-se acerca dos limites de nosso entendimento sobre a ideia ou imagem que fazem (e que fazemos) de nós mesmos. Para Kant, a ousadia de saber consistiria, essencialmente, em reconhecer os limites do próprio conhecimento. Desse modo, para fundar uma obediência legítima unicamente sobre a própria autonomia, para se pôr em questão a governamentalização, seria necessário interrogar o estatuto mesmo de nosso pensamento, a extensão e os limites das condições do conhecimento possível (ou, em outros termos, daquilo que é possível saber). De acordo com a leitura de Foucault, Kant teria fixado como tarefa fundamental do Esclarecimento o ato de fazer a crítica do próprio conhecimento, ou seja, de conhecer o conhecimento. Ousar saber implica, então, fazer com que o pensar se dobre sobre si mesmo, de modo a levar o pensamento rumo aos seus limites.

\footnotetext{
${ }^{8}$ Cabe mencionar que o termo "governamentalização", bem como os outros termos derivados da raiz "govern-“ (como governamento, governalização, governamentalidade), se encontram no cerne das reflexões de Foucault sobre a biopolítica. Sendo uma ciência do Estado, a biopolítica atuaria como uma ciência de gestão dos modos de sociabilização dos corpos. Para maiores esclarecimentos ver os verbetes Biopolítica, Governo e Poder em CASTRO. Vocabulário de Foucault - um percurso pelos seus temas, conceitos e autores.

${ }^{9}$ FOUCAULT. Qu'est-ce que la critique? Critique et Aufklärung, p. 5. (grifos nossos)
} 
No ensaio O que é Iluminismo, Foucault considera que a Era da Crítica, definida como "a passagem da humanidade para seu estado de maioridade", ${ }^{10}$ coocorre com o período histórico a que chamamos de Modernidade. Considerando que o advento histórico da crítica ocorre na Modernidade (mais precisamente no século 18), Foucault propõe que a crítica seja concebida como uma atitude que se dá como escolha voluntária “de modificação da relação entre a autoridade, a vontade e o uso da razão", ${ }^{11}$ relação esta que concerne à leitura da atualidade, do presente. $\mathrm{O}$ ato crítico, como ato de leitura da história, efetua-se como

(...) uma maneira de pensar e de sentir, uma maneira também de agir e de se conduzir que, tudo ao mesmo tempo, marca uma pertinência e se apresenta como uma tarefa. Um pouco, sem dúvida, como aquilo que os gregos chamavam de éthos. ${ }^{12}$

Dessa maneira, a crítica, compreendida enquanto éthos, constitui-se como tarefa e problema da filosofia moderna ${ }^{13}$ que questiona, simultaneamente, "a relação com o presente, o modo de ser histórico e a constituição de si próprio como sujeito autônomo”. ${ }^{14}$

Ao caracterizar o éthos filosófico que emerge com o acontecimento histórico da Aufklärung como "uma atitude de crítica permanente de nosso ser histórico", 15 Foucault coloca outro ponto: o que é nossa atualidade? Tal questão toma a forma de um pensamento crítico que postula uma investigação, em última instância, uma ontologia de nós mesmos e do que estamos a fazer conosco no presente: “(...) o que é nossa atualidade? Qual é o campo atual das experiências possíveis? Não se trata de uma analítica da verdade, tratar-se-á disso que se poderia chamar uma ontologia do presente, uma ontologia de nós mesmos (...).”16

A partir desta proposta de uma ontologia crítica do presente, e inspirado nos trabalhos de Foucault, pergunto: o que vem a ser um crítico hoje? Como esta "função-crítico", ${ }^{17}$ esta

\footnotetext{
${ }^{10}$ FOUCAULT. O que são as Luzes?, p. 341.

${ }^{11}$ FOUCAULT. O que são as Luzes?, p. 337.

${ }^{12}$ FOUCAULT. O que são as Luzes?, p. 342.

${ }^{13}$ GIACOIA JÚNIOR. Crítica e filosofia, p. 47.

${ }^{14}$ FOUCAULT. O que são as Luzes?, p. 344.

${ }^{15}$ FOUCAULT. O que são as Luzes?, p. 351.

${ }^{16}$ GIACOIA JÚNIOR. Crítica e filosofia, p. 48.

17 Seria interessante concebermos uma função-crítico, tal como Foucault propõe pensarmos as atribuições da função-autor, como uma função característica de certo modo de circulação e de funcionamento de alguns discursos dentro da sociedade, ligada ao sistema jurídico e institucional que rodeia, determina e articula o universo dos discursos. Cf. CASTRO. Vocabulário de Foucaultum percurso pelos seus temas, conceitos e autores, p. 47.
} 
figura que emerge do desdobramento da crítica da razão e da aplicação desta atitude no âmbito da esfera pública e do campo literário ${ }^{18}$ pode nos auxiliar a pensar o que estamos a fazer de nós mesmos? Como a leitura de literatura pode veicular e exercer uma intervenção, atuar como uma voz dissonante que nos alerte para nossa maioridade desinteressada pelo contemporâneo?

Gostaria que tais questionamentos ressoassem ao longo das próximas seções, nas quais veremos como esta atitude crítica, entendida como figura da racionalidade moderna, possibilitou a emergência do crítico como intelectual, desdobrou-se no exercício da crítica de arte, para, posteriormente, apontar para seu próprio esgotamento enquanto capacidade de reflexão.

\section{A TAREFA DA CRÍTICA: MEDIAÇÃO}

\section{A filosofia começa pelo meio (...) A arte começa pelo médium. ${ }^{19}$}

Ao concebermos a atitude crítica como ousadia de refletir, mostra-se pertinente considerar as propostas feitas por Walter Benjamin a respeito do ato da crítica. Márcio Seligmann-Silva, em artigo no qual discorre acerca da tarefa da crítica segundo Walter Benjamin, ${ }^{20}$ nos diz que o pensador alemão considerava a crítica, inicialmente, de acordo com o sentido kantiano - como crítica da possibilidade de conhecimento. Mesmo tomando como ponto de partida a proposta de Kant, Seligmann nos adverte que Benjamin considerava o ato da crítica como um meio de crítica de todo o sistema cultural e de sua base econômica, sendo um ato de reflexão acerca do estético e do político.

Segundo Bernardo Oliveira, o esforço de Benjamin, ao refletir sobre a crítica de arte, busca “(...) deslindar as noções de juízo e crítica”. ${ }^{21}$ Para tanto, seu ponto de partida está em bater-se contra o estado da palavra crítica no início do século 20, que, no âmbito da filosofia da arte, seria dependente da noção de juízo, sendo subordinada, enquanto ato de leitura, ao

\footnotetext{
${ }^{18}$ Categoria formulada por Pierre Bourdieu, para quem o mundo social deve ser compreendido a partir dos conceitos de campo, habitus e capital. O campo é o espaço simbólico no qual lutam agentes que legitimam representações. Cf. BOURDIEU. As regras da arte: gênese e estrutura do campo literário.

${ }^{19}$ SCHLEGEL citado por OLIVEIRA. A construção do crítico: Benjamin e os românticos, p. 28.

${ }^{20}$ SELIGMANN-SILVA. Walter Benjamin e a tarefa da crítica.

${ }^{21}$ OLIVEIRA. A construção do crítico: Benjamin e os românticos, p. 26.
} 
julgamento de valor da obra de arte - e, posteriormente à escolha do que seria digno (ou não) de tal estatuto.

Em sua tese $O$ conceito de crítica de arte no romantismo alemão, Benjamin estabelece que a atividade da crítica seria “(...) geralmente identificada com a avaliação e recomendação de certas obras em detrimento de outras (...)”."22 Já o crítico “(...) seria aquele que trava uma batalha particular a favor do que merece ser lido, visto ou escutado e contra o que não merece, baseado para tanto em algum critério distintivos mais ou menos claro”. ${ }^{23}$ Deste ponto de vista, a concepção de crítica teria, então, certo “(...) caráter pedagógico e media a relação entre a obra com um público determinado”. ${ }^{24}$

É pertinente observar que tal “caráter pedagógico” da crítica de arte se encontra relacionado a um certo modo de direcionamento da consciência, mais precisamente a um direcionamento da formação do juízo de apreciação, ou juízo de gosto estético. Se considerarmos que o ético, o estético e o político são indissociáveis, então a formação de juízo e o direcionamento da consciência podem ser considerados como expressões correlatas atuantes na elaboração de formas de subjetivação.

A partir da concepção dos românticos de crítica como conhecimento que ocorre enquanto conexão de reflexões (concepção que implica não haver uma reflexão inicial, originária, mas conexões entre especulações), Benjamin tenta conceber a crítica como

(...) um processo de conexão entre reflexões que (...) se dá como relação entre discursos. O nome para este processo, centrado na conexão, é "médium de reflexão”, onde, na palavra médium, devemos escutar a noção de um elemento transmissor, ou mesmo a própria transmissão. ${ }^{25}$

De acordo com Seligmann, a proposta de crítica feita por Benjamin ${ }^{26}$ se desdobrava em cinco níveis: em primeiro lugar, uma autorreflexão, na qual o crítico refletia sobre sua própria atividade, o local e o papel da crítica na sociedade. Em segundo, uma leitura detalhada e uma reflexão sobre a obra criticada. Em terceiro, uma reflexão sobre a história da arte e da literatura. Em quarto, uma reflexão crítica sobre a sociedade a partir do seu presente e voltada

\footnotetext{
${ }^{22}$ OLIVEIRA. A construção do crítico: Benjamin e os românticos, p. 26. (grifos nossos)

${ }^{23}$ OLIVEIRA. A construção do crítico: Benjamin e os românticos, p. 26. (grifos nossos)

${ }^{24}$ OLIVEIRA. A construção do crítico: Benjamin e os românticos, p. 26. (grifos nossos)

${ }^{25}$ OLIVEIRA. A construção do crítico: Benjamin e os românticos, p. 28.

${ }^{26}$ Cf. SELIGMANN-SILVA. Walter Benjamin e a tarefa da crítica.
} 
para ele. Por fim, a articulação de todos os níveis anteriores em uma crítica aos modelos históricos.

Ao conceber a crítica como uma hermenêutica reflexiva, não judicativa, Benjamin (segundo a leitura de Oliveira) insiste que uma filosofia da arte que se queira crítica, “deve ser fundada na criticabilidade e não na julgabilidade [sendo que] (...) a criticabilidade implica uma articulação da obra com os discursos a ela associados”. ${ }^{27}$ Dessa forma, o critério para o estabelecimento de uma obra de arte, do elemento específico da experiência da arte (sua imanência), seria o fato de a obra ser criticável ou não. A crítica "para ele só existia enquanto capacidade de se articular (...) a imanência da obra com a reflexão histórico-crítica”. ${ }^{28}$ A obra criticável ocasionaria a conexão com outras reflexões, a partir dos critérios fornecidos pela própria obra, intensificando a reflexão - propiciando à atividade crítica que o jogo infinito das leituras se sucedam, em um livre jogo de perspectivas, sem que nenhuma delas se revele como definitiva.

Desse modo, Benjamin buscou desvincular as noções de crítica e de juízo, a fim de recriar a crítica como gênero, formulando-a como um meio de leitura crítica não apenas do sistema estético, mas da linguagem e de toda a sociedade.

Na seção seguinte, propõe-se que repensemos as relações entre a representação do crítico como intelectual e seu compromisso com a mediação do texto literário.

\section{O CRÍTICO COMO INTELECTUAL: COMPROMISSO COM A LEITURA}

Da paixão de um cocheiro e de uma lavadeira.

Tagarela, nasceu um rebento raquítico. Filho não é bagulho, não se atira na lixeira. A mãe chorou e o batizou: crítico. ${ }^{29}$

Em entrevista ${ }^{30}$ sobre seu livro $O$ enigma vazio: impasses da arte e da crítica, o poeta e teórico Affonso Romando de Sant'Anna, ao discorrer sobre a necessidade de se empreender uma crítica da crítica, a fim de que se reflita sobre os caminhos da arte na atualidade, menciona três tipos de atividade crítica: a crítica informativa (de caráter jornalístico, uma prestação de serviço público com função de divulgar), a celebrativa (crítica do endosso,

\footnotetext{
${ }^{27}$ OLIVEIRA. A construção do crítico: Benjamin e os românticos, p. 29.

${ }^{28}$ Cf. SELIGMANN-SILVA. Walter Benjamin e a tarefa da crítica.

${ }^{29}$ MAIAKÓVSKI. Hino ao Crítico, p.181.

${ }^{30}$ SANT’ANNA. Entrevista ao jornalista Pedro Henrique Ferreira.
} 
espécie de colunismo social) e a reflexiva (ou acadêmica, que se volta para a análise objetiva de obras e autores). De acordo com o poeta, é imprescindível que repensemos as práticas destes três modos, visto que apresentam sinais de esgotamento.

No poema de Fabrício Marques, é possível observarmos as relações entre os três tipos de crítica atuando na configuração de uma rede literária:

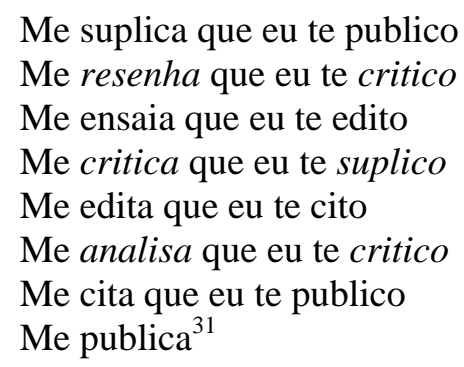

Esse poema ilustra, de certa forma, as considerações que se seguem sobre a configuração do campo literário e a função da crítica literária na atualidade. Nele, podemos observar a tematização bem-humorada do círculo vicioso que configura o sistema literário e o sistema crítico. ${ }^{32}$ Tal círculo vicioso (e viciado, podemos acrescentar) ocorre pela relação entre: a crítica literária institucionalizada, veiculada em jornais e suplementos culturais ou por instituições universitárias; pela relação entre os “pares”, sejam acadêmicos, escritores ou jornalistas que atuam como críticos literários; pela relação entre indústria cultural, editores e livreiros. Estes são alguns dos possíveis elementos que compõem esta equação, sendo que esta não se resume aos termos elencados.

Gostaria de lembrar algumas provocações feitas pelo sociólogo Daniel Lins, a fim de que elaboremos um esboço do crítico como intelectual. Em texto intitulado O novo papel do intelectual, Lins discorre sobre o problema do intelectual como consciência

${ }^{31}$ Grifos de minha autoria. O poema "Mini litania da política editorial", de autoria de Fabrício Marques (MARQUES citado por COSTA. Pena de aluguel: escritores e jornalistas no Brasil, 1904-2004, p. 171), é mencionado no livro Pena de aluguel: jornalistas e escritores no Brasil, 1904-2004 (COSTA. Pena de aluguel: escritores e jornalistas no Brasil, 1904-2004), como parte do depoimento cedido pelo escritor para a pesquisa do qual o livro resulta. O depoimento se encontra disponível no site projeto: <http://www.penadealuguel.com.br/entrevistas/news.asp?cod1=24>. Acesso em: 20 out. 2009.

${ }^{32}$ Por sistema crítico compreende-se a triangulação entre crítico, objetos culturais e público. Tal conceito, apresentado por Jacques Leenhardt, toma como base a proposta de sistema literário formulada por Antonio Candido e Ángel Rama. Para maiores informações, ver MARTINS. Rumos da crítica, p. 13. 
representante/representativa da opinião pública, em razão da menoridade desta frente ao Estado e às questões políticas e culturais de sua época. ${ }^{33}$

A partir da questão da "menoridade da opinião pública”, menoridade aludida por Foucault em sua leitura de Kant, Lins questiona qual seria o papel do intelectual face a tal menoridade do uso crítico da razão: “(...) qual seria [então] o lugar do intelectual? O papel do intelectual não é o de dizer aos outros o que devem fazer. (...) O intelectual é apenas um homem; sua consciência não vale mais que a de um outro.”34

Se o intelectual é apenas um homem cuja consciência não vale mais que a de um outro, o que diferencia sua fala dos demais homens? O que o outorga direitos de se postular como formador (ou mediador) de consciência crítica a partir da reflexão sobre os limites dos modos de ler e conhecer o mundo, a arte, a cultura e nós mesmos? Lins fornece alguns elementos para nossa equação: "O conhecimento se constitui como fundamento da razão crítica e como bem universal.”35 Se o conhecimento é o fundamento que viabiliza a razão crítica, então “o que caracteriza o intelectual [e o crítico] é fazer uso público do conhecimento". 36

Renato Janine Ribeiro, ao interrogar a historicidade da noção de intelectual público, pergunta: “há intelectual que não seja público?”37 De acordo com o filósofo, “o intelectual não poderia ser mais antigo que o Iluminismo”. ${ }^{38}$ Filho da Era da Crítica, o trabalho do crítico-intelectual se constitui em "transferir para o grande público um conhecimento que antes era encerrado entre os que podiam saber”. ${ }^{39}$

Mais adiante, Ribeiro nos fornece outro traço característico do crítico-intelectual:

(...) o intelectual é mais quem discute a apropriação do conhecimento do que aquele que o difunde. O papel do intelectual consiste em articular valores e conhecimentos, idéias e ideais. $\mathrm{O}$ intelectual debate o valor da ciência (....). ${ }^{40}$

\footnotetext{
${ }^{33}$ LINS. O novo papel do intelectual, p. 229.

${ }^{34}$ LINS. O conhecimento é um bem público, p. 95.

${ }^{35}$ LINS. O conhecimento é um bem público, p. 95.

${ }^{36}$ RIBEIRO. O cientista e o intelectual, p. 141.

${ }^{37}$ RIBEIRO, RIBEIRO. O cientista e o intelectual, p. 137.

${ }^{38}$ RIBEIRO, RIBEIRO. O cientista e o intelectual, p. 141.

${ }^{39}$ RIBEIRO, RIBEIRO. O cientista e o intelectual, p. 141.

${ }^{40}$ RIBEIRO, RIBEIRO. O cientista e o intelectual, p. 142.
} 
De acordo com essa consideração do filósofo, o intelectual seria, então, aquele que divulga, e, nesse trabalho, lida com o valor, discutindo a atribuição de valor às coisas. Ele “(...) é quem vincula o conhecimento ao seu valor, uma vez que, ao debater o valor das idéias, pensa sob a forma de mediação". 41

A partir das atribuições elencadas, é possível elaborarmos um esboço: o crítico seria aquele que estabelece as mediações necessárias entre a criação artística, o trabalho acadêmico, científico e sua apropriação social, atuando como leitor dos avanços do conhecimento, sendo “a voz provisória do público”42. Seu compromisso seria, portanto, o de formar um público, uma cena, uma ágora. “O intelectual leva à praça a discussão da ciência (como outras discussões)" 43

A partir deste comentário, Janine Ribeiro coloca as seguintes questões:

Se faz mediações, qual é então sua relação com a mídia? A hipótese inicial é de que ele de alguma forma se articula com ela. O que seria um intelectual sem opinião pública? Sem a idéia de uma doxa ampliada, de um sensus communis, o que resta do intelectual? ${ }^{44}$

Ao questionar a relação do crítico-intelectual, caracterizado até então como mediador do conhecimento, com a mídia que o conecta à opinião pública, o filósofo questiona qual seria a natureza da relação entre o intelectual e a mídia e, por extensão, a diferença entre o papel do crítico-intelectual e do jornalista.

Esta relação, entre as diferenças do crítico-intelectual e do jornalista, remete diretamente à questão da crise da crítica literária brasileira. Sobre esse assunto, a notícia mais antiga data do embate entre Afrânio Coutinho e Álvaro Lins em fins da década de 1940, discussão que foi provocada pela falta de empatia e sincronia entre duas hermenêuticas bastante temperamentais: a da crítica universitária e a da crítica jornalística. Passados mais de 60 anos, qual o cenário? De um lado, a crise da chamada crítica de rodapé (em razão de problemas financeiros vivenciados pelos principais periódicos nacionais), de outro, a acusação de isolamento da crítica acadêmica nos periódicos universitários.

\footnotetext{
${ }^{41}$ RIBEIRO. O cientista e o intelectual, p. 146-147.

${ }^{42}$ Cf. LEENHARDT. Crítica de arte e cultura no mundo contemporâneo, p. 20.

${ }^{43}$ RIBEIRO. O cientista e o intelectual, p. 146.

${ }^{44}$ RIBEIRO. O cientista e o intelectual, p. 147.
} 
O professor Paulo Franchetti, no texto "A demissão da crítica”, argumenta que “o relaxamento da [atividade] crítica no interior da universidade” ${ }^{45}$ é responsável pelo processo geral de rarefação e enfraquecimento da crítica junto à sociedade. Ainda segundo o professor da Unicamp, a eliminação do tom dissonante que sustenta a tensão crítica seria o que ocasiona a demissão (ou falência momentânea) da crítica da vida literária (e intelectual) brasileira. Tal quadro seria resultante da convergência entre interesses gerados pelo fortalecimento do mercado editorial, por um lado, e o enfraquecimento do meio intelectual, por outro.

A este esboço de contexto (de falência do crítico como intelectual e mediador do conhecimento) gostaria de passar ao texto de Silviano Santiago, “Outubro retalhado”, a fim de potencializar a discussão. Nesse texto, o autor coloca o problema da função e do valor da literatura, o papel do escritor e do intelectual na atualidade. Santiago parte de dois eventos, ambos relacionados a duas instâncias de legitimação da instituição Literatura (o Prêmio Nobel e a Feira do Livro de Frankfurt) para esboçar estas questões. Outros questionamentos apontados pelo texto dizem respeito à "responsabilidade do escritor no interior das falas institucionais hegemônicas" e ao "conteúdo da biografia do escritor no contexto dos partidos políticos e instituições no poder". 46 Sobre estes dois últimos pontos, sugiro que, em consonância a proposta deste ensaio, onde se lê escritor, leia-se crítico.

Após enumerar três entidades, dotadas de atributos específicos, em cena no tabuleiro literário do novo milênio (o romancista de qualidade, representante da arte; o autor recordista, que representa a indústria cultural; a intelectual participante, que levanta a bandeira da política), o autor delimita a proposta de livro que vigora atualmente no campo literário: a do stock exchange, que move a bolsa de valores da República Literatura.

Retornando aos comentários de Paulo Franchetti, “o crítico literário - tanto o da imprensa quanto o das universidades - é, para os escritores de hoje, uma nova espécie de colunista social”, ${ }^{47}$ De acordo com a proposta de livro apresentada por Silviano Santiago (que parte da premissa do fortalecimento do mercado editorial como instância legitimadora) e a leitura de Franchetti do exercício do crítico que vigora na atualidade, a crítica contemporânea é mais propriamente descrita como modalidade de marketing, que se apresenta, de certa forma, em consonância à lógica do stock exchange - que funciona como voz que orienta o

\footnotetext{
${ }^{45}$ FRANCHETTI. A demissão da crítica.

${ }^{46}$ SANTIAGO. Outubro retalhado (entre Estocolmo e Frankfurt), p. 30-31.

${ }^{47}$ FRANCHETTI. A demissão da crítica.
} 
leitor sobre tendências e que vende novos talentos de acordo com os humores das feiras e demais eventos promotores da literatura.

Gostaria de me deter em outro questionamento colocado por Santiago e que também se faz presente no texto de Franchetti: o compromisso do discurso (filosófico, crítico e literário). O autor relembra os argumentos de Maurice Blanchot a respeito da adesão de Heidegger ao regime nacional-socialista na Alemanha e de seu discurso como reitor da Universidade de Freiburg durante o referido regime. De acordo com Blanchot, "Houve corrupção da escrita, abuso, travestimento e dissipação da linguagem [filosófica]. Uma suspeita pesará de agora em diante sobre ela”. ${ }^{48}$

A partir do comentário (de Blanchot sobre Heidegger), considero pertinente refletirmos acerca das tópicas da responsabilidade e do compromisso da crítica: qual(is) seria(m) o(s) compromisso(s) e a(s) função(ões) do discurso da crítica literária? Tomando como base as reflexões elencadas até o momento (a atitude crítica como ousadia, o compromisso do crítico-intelectual com a mediação, com a educação da sensibilidade, com a formação de uma cena na qual a tensão seja o motor de uma saúde reflexiva), o compromisso da crítica seria o de estabelecer pontes entre o impulso de interrogação do real que há no texto literário e o público leitor, excitando sua curiosidade, auxiliando-o a (re)educar o olhar. Como nos lembra Jacques Leenhardt, “o texto crítico funciona (...) como uma escola do ver, uma pedagogia da sensibilidade”. 49

Em um momento em que o campo literário (e o crítico) se apresenta como um jogo de xadrez, em que as possibilidades parecem ser infinitas, mas os movimentos se mostram limitados pela determinação do estatuto das peças, talvez o melhor seja efetuar o deslocamento do conceito, da práxis e dos pressupostos norteadores da crítica.

\section{DESLOCAR PARA CRIAR: UM COMPROMISSO COM O POSSÍVEL}

De acordo com Vladimir Safatle, ${ }^{51}$ vivemos o esgotamento do que convencionamos chamar de “crítica”. Segundo o referido autor, tal vivência nos impele a vislumbrar os

\footnotetext{
${ }^{48}$ SANTIAGO. Outubro retalhado (entre Estocolmo e Frankfurt), p. 34.

${ }^{49}$ LEENHARDT. Crítica de arte e cultura no mundo contemporâneo, p. 20.

${ }^{50}$ MELO NETO. Psicologia da composição, p. 170.
} 
fundamentos de uma forma de atividade crítica renovada. A esse esgotamento, Safatle chama de cinismo, ou atitude cínica. Tal cinismo seria compreendido como uma figura de racionalidade que estabelece como premissa que "só é possível ser racional sendo cínico”. 52 Seria o caso de perguntarmos: da razão crítica à razão cínica, o que se passou? Safatle propõe uma genealogia do cinismo como figura de racionalidade derivada do esgotamento do projeto kantiano de crítica da razão que, no campo da arte, reveste-se de uma ironia formal para mascarar o esgotamento expressivo em que se encontra.

Benedito Nunes nos sugere que "talvez seja mesmo a crise da crítica o efeito exterior de uma crise da própria literatura, combalida, intoxicada, inconfortada, maquilada dentro do vigente sistema de valores mediáticos da vida cultural brasileira”. ${ }^{53} \mathrm{Na}$ mesma direção, Leyla Perrone-Moisés insiste que "não pode existir crítica literária se não houver um conjunto de valores estéticos reconhecidos e, por conseguinte, um cânone de referência. Não pode mais existir crítica se não houver um conceito forte de literatura”. ${ }^{54}$ Ou seja: sem um conjunto de valores de referência estável (um cânone), não há um conceito de literatura - e, portanto, não há condições para o exercício da reflexão a que chamamos de crítica, já que esta depende da partilha de valores estabelecidos "consensualmente". Como adverte Benedito Nunes, se "a literatura cai, a crítica despenca”. 55

A partir das questões colocadas anteriormente, considero pertinente nos perguntarmos se as instâncias de legitimação (o Nobel, as bienais, feiras internacionais de livro, as universidades, as políticas escolares da leitura de literatura, os prêmios literários etc.) não atuariam como dispositivos ${ }^{56}$ de manutenção da razão cínica? Se considerarmos o diagnóstico oferecido por Safatle, de que tal cinismo se dá em decorrência de um processo de “esgotamento de padrões de racionalidade normativa e valoração que se confundem com uma certa história da modernidade filosófica, onde crítica social e crítica da razão se entrelaçam”, 57

\footnotetext{
${ }^{51}$ SAFATLE. Cinismo e falência da crítica, p. 12.

${ }^{52}$ SAFATLE. Cinismo e falência da crítica, p. 13.

${ }^{53}$ NUNES. Crítica literária no Brasil, ontem e hoje, p. 74.

${ }^{54}$ Cf. PERRONE-MOISÉS. Que fim levou a crítica literária?, p. 340-341.

${ }^{55}$ NUNES. Crítica literária no Brasil, ontem e hoje, p. 75.

${ }^{56}$ Sobre o conceito de dispositivo, Seligman-Silva propõe que seja concebido como "uma confluência entre uma reflexão sobre o poder e uma teoria da técnica”. SELIGMANN-SILVA. Éléos, compaixão e piedade na origem da (est)ética contemporânea: o dispositivo trágico e o olhar de/sobre o outro.

${ }^{57}$ SAFATLE. Cinismo e falência da crítica, p. 15-16.
} 
inclino-me a pensar que a temerária resposta seria um (cínico?) “eu preferiria não” - mas, ao que tudo indica, parece-me que sim.

Parece que o valor e a função da literatura, bem como o papel e função do crítico se encontram subordinados a um jogo. Tal jogo parece ocorrer devido à interação entre os termos desejo, poder e interesse, nos quais o desejo ("este grande desconhecido" ${ }^{58}$ ) investe no exercício de poder, visando à manutenção de modos de satisfação de interesses específicos no caso, a manutenção do conceito de cânone e, por conseguinte, da instituição Literatura. Não tenho a pretensão de delimitar ontologicamente “o que são” os três termos, mas de pontuar que, a economia libidinal (ou desejante), à qual alude Safatle, efetua-se, como mencionam Foucault e Deleuze, ${ }^{59}$ como um jogo de relações que visa à satisfação de interesses específicos e à produção de modos de vida.

Penso que tal “jogo” coloca, para nós, não apenas o problema da noção de valor mas, tal como formulado por Nietzsche, a questão do valor dos valores, da avaliação de onde procede seu valor. ${ }^{60}$ Se o cânone se estabelece em razão de interesses, em que condições (e como) se viabiliza tal atribuição? Se, como propõe Giacoia, o crítico atua como a "máconsciência de sua época”, ${ }^{61}$ como esta consciência crítica se expressaria a respeito da própria demissão, ${ }^{62}$ a propósito do próprio conformismo em relação a sua “desfunção”?

Diante dos diagnósticos de falência e esgotamento da crítica, seria possível apresentar uma proposta de crítica renovada que relacione (como sugere Safatle) uma crítica social, uma crítica da razão e uma análise das produções culturais? Seria possível elaborar uma proposta que nos auxilie a repensar a literatura e a crítica enquanto médium-de-reflexão?

Ao considerar a invectiva de Safatle, de que “(...) só resta à crítica ser crítica dos modos de satisfação que legitimam nossas formas de vida”, ${ }^{63}$ penso que é possível vislumbrar uma possibilidade de renovação do ato crítico, em que ecoe a pergunta feita por Foucault - o que estamos a fazer de nós mesmos e de que é nossa atualidade? Para tanto, seria preciso

${ }^{58}$ Cf. DELEUZE. Os intelectuais e o poder (com Michel Foucault), p.272.

${ }^{59}$ DELEUZE. Os intelectuais e o poder (com Michel Foucault), p. 272.

${ }^{60}$ DELEUZE. Nietzsche e a filosofia, p. 06.

${ }^{61}$ GIACOIA JÚNIOR. Crítica e filosofia, p. 44.

${ }^{62}$ Refiro-me à expressão empregada por Giacoia para referir-se à atividade reflexiva que se adapta resignadamente, passivamente, ao atual, sem se ocupar em apresentar alternativas criativas de outros modos de questionar e conceber o presente.

${ }^{63}$ SAFATLE. Cinismo e falência da crítica, p. 27. 
deslocar em relação a certa dóxa (como sugere Perrone-Moisés) para ousar, de outra forma, criar.

Se considerarmos que a crítica sempre esteve em crise (como lembra Benedito Nunes, crise não é catástrofe, mas incerteza), ${ }^{64}$ é necessário "auxiliá-la” a se deslocar, reavaliando posturas teóricas e os valores que as embasam, tais como os conceitos de cânone e de literatura, a fim de que se elaborem novos conceitos e práticas adequados às demandas do contemporâneo.

A partir desta sugestão de renovação da atitude crítica, face ao esgotamento do compromisso da mesma com a produção de leituras do humano, seria necessário nos perguntarmos: o que vem a ser um crítico? Como se faz crítica? Quais os jogos de representações que formam a imagem do cânone, da literatura e da crítica hoje? Como seria possível fomentar o atrito e a tensão crítica? Estas são algumas questões que se impõem a partir das considerações de Foucault, Benjamin, Deleuze, Silviano Santiago, Paulo Franchetti, Safatle, Perrone-Moisés, Benedito Nunes e Giacoia Junior. É necessário indagar-nos sobre os sentidos do próprio ato crítico e sobre o alcance e repercussão pública da crítica - não para continuarmos a efetuar diagnósticos de cunho terminal, mas para tentarmos apresentar alternativas e modos de imaginar novos cenários de intervenção.

Em ressonância ao trecho do poema que serve de epígrafe ao final deste ensaio, se o deserto e a esterilidade se apresentam como as possibilidades de exercício da crítica (como o jardim que o contemporâneo nos permite), então que a aridez e o esgotamento sejam a condição do cultivo de uma fertilidade outra - de uma práxis crítica que não apenas ouse saber interpretar a criação literária, mas que, a partir da literatura (e com ela), ouse se deslocar, a fim de que sejam possíveis outros modos de leitura do contemporâneo.

\begin{abstract}
This paper proposes a reading of the concept of criticism from discussions on the context and practice of literary criticism in Brazil today. It aims to reflect on the duty of the critic as a mediator of literature and contemporaneity to the reading public.
\end{abstract}

\title{
KEYWORDS
}

Literature, criticism, mediation

\footnotetext{
${ }^{64}$ NUNES. Crítica literária no Brasil, ontem e hoje, p. 74.
} 


\section{REFERENNCIAS}

BOURDIEU. As regras da arte: gênese e estrutura do campo literário. 2. ed. Trad. Maria Lúcia Machado. São Paulo: Companhia das Letras, 1996

CASTRO, Edgardo. Vocabulário de Foucault - um percurso pelos seus temas, conceitos e autores. Trad. Ingrid Müller Xavier. Belo Horizonte: Autêntica, 2009.

COSTA, Cristiane. Pena de aluguel: escritores e jornalistas no Brasil, 1904-2004. São Paulo: Companhia das Letras, 2005.

DELEUZE, Gilles. Nietzsche e a filosofia. Porto: Rés-Editora, [19--].

DELEUZE, Gilles. Os intelectuais e o poder (com Michel Foucault). Trad. Luiz B. L. Orlandi et al. In: _. A ilha deserta e outros textos: textos e entrevistas (1953-1974). São Paulo: Iluminuras, 2006. p. 265-273.

FOUCAULT, Michel. O que são as Luzes? In: Arqueologia das ciências e história dos sistemas de pensamento. 2. ed. Trad. Elias Monteiro. Rio de Janeiro: Forense Universitária, 2008. p. 335-351. (Ditos e escritos, 1).

FOUCAULT, Michel. Qu'est-ce que la critique? Critique et Aufklärung. Bulletin de la Société française de Philosophie, v. 82, n. 2, p. 35-63, avr./juin. 1990. (Conferência proferida em 27 de maio de 1978). O que é a crítica? Tradução: Gabriela Lafetá Borges. Disponível em: < http://vsites.unb.br/fe/tef/filoesco/foucault/critica.pdf >. Acesso em: 14 ago. 2009.

FRANCHETTI, Paulo. A demissão da crítica. Disponível em: <http://www.germinaliteratura.com.br/enc_pfranchetti_abr5.htm>. Acesso em: 20 fev. 2010.

GIACOIA JÚNIOR, Oswaldo. Crítica e filosofia. Revista Temas \& Matizes. Dossiê Biopolítica. Cascavel: Universidade Estadual do Oeste do Paraná, 2007, v. 6, n. 11, p. 41-50.

HOUAISS, Antônio; VILLAR, Mauro; FRANCO, Francisco Manoel de Mello. Dicionário eletrônico Houaiss da língua portuguesa. Rio de Janeiro: Objetiva/Instituto Antonio Houaiss, 2001. CD-ROM.

LEENHARDT, Jacques. Crítica de arte e cultura no mundo contemporâneo. In: MARTINS, Maria Helena (Org.). Rumos da crítica. São Paulo: Editora SENAC/Itaú Cultural, 2000. p. 19-28.

LIMA, Rachel Esteves. Crítica Literária: da disciplina ao descontrole. Disponível em: <www.cult.ufba.br/enecult2008/14612.pdf>. Acesso em: 20 fev. 2010.

LINS, Daniel. O conhecimento é um bem público. In: . O dedo no olho: micropolíticas do cotidiano. São Paulo: Annablume, 1999. p. 95-97.

LINS, Daniel. O novo papel do intelectual. In: cotidiano. São Paulo: Annablume, 1999. p. 229-230.

O dedo no olho: micropolíticas do

MAIAKÓVSKI, Vladimir. Hino ao crítico. In: CAMPOS, Augusto de; CAMPOS, Haroldo de; SCHNAIDERMAN, Boris. Poesia russa moderna: nova antologia. 5. ed. rev. e ampl. São Paulo: Brasiliense, 1987. p. 181-182.

MALHADAS, Daisi; DEZOTTI, Maria Celeste Consolin; NEVES, Maria Helena de Moura. Dicionário grego-português: [DGP]. Cotia: Ateliê Editorial, 2008. v. 3.

MARTINS, Maria Helena (Org.). Rumos da crítica. São Paulo: Editora SENAC/Itaú Cultural, 2000. 
MORICONI, Ítalo (Org.). Os cem melhores poemas brasileiros do século. Rio de Janeiro: Objetiva, 2001.

MELO NETO, João Cabral de. Psicologia da composição. In: MORICONI, Os cem melhores poemas brasileiros do século. Rio de Janeiro: Objetiva, 2001. p. 165-170.

NUNES, Benedito. Crítica literária no Brasil, ontem e hoje. In: MARTINS, Maria Helena (Org.). Rumos da crítica. São Paulo: Editora SENAC/Itaú Cultural, 2000. p. 51-79.

OLIVEIRA, Bernardo Barros Coelho de. A construção do crítico: Benjamin e os românticos. Artefilosofia, Ouro Preto: Instituto de Filosofia, Artes e Cultura, 2009, n. 6, p. 26-33.

OLIVEIRA, Nelson de. Uma cajadada no cocoruto da crítica: como nossos críticos tornaramse reféns da rede de produção e circulação de livros. Disponível em:< http://voos.sites.uol.com.br/capas/05/11nelson.htm>. Acesso em: 20 fev.2010.

PERRONE-MOISÉS, Leyla. Que fim levou a crítica literária? In: Inútil poesia e outros ensaios breves. São Paulo: Cia. das Letras, 2000. p. 335-344.

RIBEIRO, Renato Janine. O cientista e o intelectual. In: NOVAES, Adauto (Org.). O silêncio dos intelectuais. São Paulo: Cia. das Letras, 2006. p. 137-149.

SAFATLE, Vladimir. Cinismo e falência da crítica. São Paulo: Boitempo, 2008.

SANT'ANNA, Affonso Romano. Entrevista ao jornalista Pedro Henrique Ferreira. Disponível em: <http://www.gargantadaserpente.com/entrevista/affonsoromano3.shtml>. Acesso em: 16 dez. 2009.

SANTIAGO, Silviano. Outubro retalhado (entre Estocolmo e Frankfurt). In: MARGATO, Izabel; GOMES, Renato Cordeiro (Org.). O papel do intelectual hoje. Belo Horizonte: Editora UFMG, 2004. p. 23-38.

SELIGMANN-SILVA, Márcio. Walter Benjamin e a tarefa da crítica. Revista Cult. Texto disponível em: <http://revistacult.uol.com.br/website/dossie.asp?edtCode=9E022936-7BFD42CD-832E-738C5FA7F3C7\&nwsCode=3C7492E8-CF52-43CA-A483-23921D5BB2C8> . Acesso em: 22 nov. 2009.

SELIGMANN-SILVA, M.. Éléos, compaixão e piedade na origem da (est)ética contemporânea: o dispositivo trágico e o olhar de/sobre o outro. 2008. (Texto inédito distribuído na oficina "A violência na literatura e no cinema", ocorrida no $39^{\circ}$ Festival de Inverno da UFMG, em 2008). 